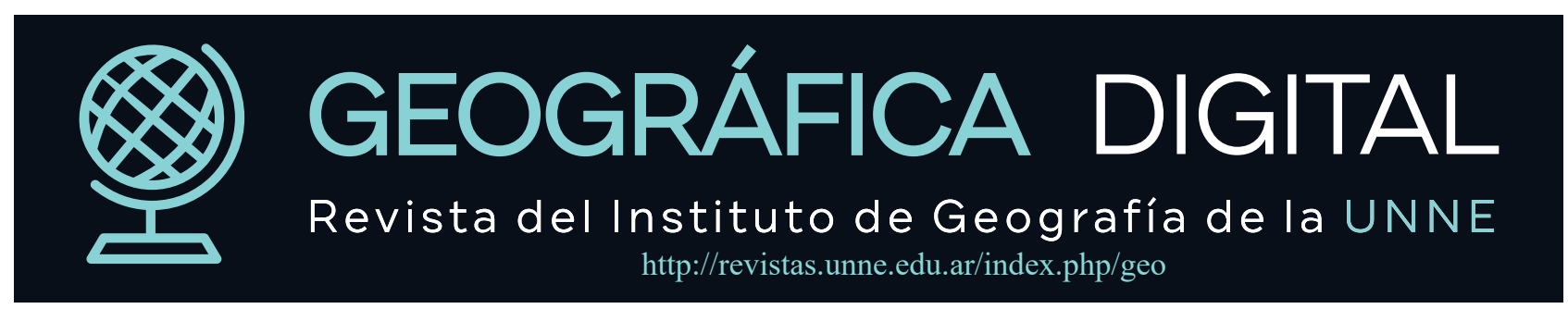

Revista Geográfica Digital, 2021, Vol. 18, No 36, 2-19 pp., E-ISSN: 1668-5180: DOI: http://dx.doi.org/10.30972/geo.18364682

\title{
Cartografías de movilidad. ATLAS ENcuesta MOvilidad DOmiciliaria (ENMODO) del AMBA, 2009-2010
}

\section{Cartographies of mobility. Atlas from AMBA Household mobility survey (ENMODO), 2009-2010}

\author{
Gutiérrez, Andrea I. ${ }^{1}$; Pereyra, Leda P.M² \\ ${ }^{1}$ Licenciada y Doctora en Geografía. CONICET-UBA/ IIGEO-Programa Transporte y Territorio. angut2@gmail.com \\ 2Licenciada en Sociología - Doctoranda en Geografía. UBA/IIGEO-Programa Transporte y Territorio. pereyra.leda@gmail.com
}

\begin{abstract}
R E S U M E N
Palabras Claves:

Movilidad

Cartografía

Metodologías

Políticas públicas

Las Encuestas de Movilidad Domiciliaria (ENMODO) son una fuente oficial de datos estadísticamente representativos de la movilidad cotidiana de aglomerados urbanos, a escala macro y por todos los motivos y modos de transporte. Resultan clave tanto para políticas públicas como para investigaciones académicas, para elaborar diagnósticos, observar tendencias, definir líneas de base o contextualizar información proveniente de otras fuentes. Siendo la movilidad parte indisoluble de lo territorial, el análisis espacial es una metodología clave del estudio territorial (Gutiérrez, 2020). Sin embargo, el análisis espacial de las ENMODO es débil, y en particular la cartografía que acompaña la publicación de sus resultados.

El objetivo del trabajo es aportar a la producción de cartografía temática y analítica sobre movilidad cotidiana, basada en la utilización de los datos cuantitativos ofrecidos por las ENMODO. En lo metodológico, se trabaja con el caso de la ENMODO 2009-2010 realizada en el Área Metropolitana de Buenos Aires, recuperando aprendizajes y desarrollos vinculados con la elaboración de un Atlas. Como aporte empírico se presenta la tipología y los criterios de selección de las cartografías de movilidad resultantes. El principal hallazgo versa acerca de la factibilidad de una mayor explotación cartográfica de las ENMODO como medio para generar información nueva, útil para la gestión del territorio, y accesible a un público amplio.
\end{abstract}

Keywords:

Mobility

Cartography

Methodologies

Public policies

Recibido: 03/03/2021

Aceptado: 16/11/2021

\section{A B S T R A C T}

The Household Mobility Surveys (ENMODO by its acronym in Spanish) are an official source of statistically representative data on the daily mobility of urban agglomerates, on a macro scale and by all modes of transport. These are key for both public policies and academic research, to make diagnoses, observe trends, define baselines or contextualize information from other sources. Being mobility an indissoluble part of the territorial, and spatial analysis a key methodology of the territorial studies (Gutiérrez, 2020), curiously, the spatial analysis of the ENMODO is weak, particularly its cartography.

The paper aims to contribute to generate thematic and analytical cartography on daily mobility, based on the use of quantitative data offered by the ENMODO. Regarding methodology, the case of ENMODO 2009-2010 carried out in the Metropolitan Area of Buenos Aires is used, recovering learnings and developments related to the elaboration of the Atlas. As an empirical contribution, the typology and selection criteria of the resulting mobility maps are presented. The main finding is about the feasibility of a greater cartographic exploitation of the ENMODO as a way to create new information, useful for land management, and accessible to a wider audience. 


\section{Introducción}

La movilidad es una dimensión de lo territorial y es, asimismo, constitutiva de la dinámica de las territorialidades. Es condición y resultado de la localización de las actividades y de las personas, así como de los flujos entre lugares (Gutiérrez, 2020). Esto aplica a la movilidad cotidiana o aquella de mayor duración (en permanencia o distancia) y a la movilidad de las personas o de los bienes.

Curiosamente, muchas de las técnicas de estudio más convencionales en el campo de la movilidad y el transporte son débiles en lo espacial o los análisis débilmente territorializados, sobre todo en América Latina y en particular en el contexto argentino.

Un buen ejemplo de ello lo constituyen las Encuestas de Movilidad Domiciliaria (en adelante, ENMODO). Las ENMODO son una fuente de información oficial, estadísticamente representativa -y geográficamente referenciable- de los grandes volúmenes de viajes que hacen a la movilidad de las personas en los aglomerados urbanos, capturados éstos en su conjunto, esto es, a escala macro o metropolitana, por todos los motivos de actividad y modos de transporte.

Si bien la información obtenida por su intermedio es susceptible de análisis espacial y de representación cartográfica, esta utilidad es poco explotada tanto por la gestión como por los estudios en el campo del desplazamiento territorial, incluyendo esto al propio proceso que forma parte de la elaboración y producción de sus resultados: a nivel nacional como internacional, las publicaciones de resultados de las ENMODO tienen una carencia notable de mapas. Este déficit repercute en la utilidad pública de la información derivable, dado que el tratamiento de las bases de datos de una ENMODO requiere capacidades previas y específicas.

En Argentina, tras décadas de ausencia de información oficial, entre 2009 y 2010 se llevó a cabo una ENMODO en el Área Metropolitana de Buenos Aires (AMBA), principal aglomerado urbano del país. Pese a las demoras habidas en la publicación de sus resultados, éstos son de acceso público así como las correspondientes bases de datos, hecho que no sucedió con las encuestas posteriores. No obstante esta relevancia, la publicación de los resultados de la ENMODO 2009-2010 comparte y mantiene la misma paradojal debilidad: una carencia de mapas.

Esta situación amerita indagar en las posibilidades de representación cartográfica de los resultados de las ENMODO, tanto en términos de los aportes derivables en lo metodológico como de la información contenida. Aunque la ENMODO AMBA 2009-2010 tiene una década de vida, la información que aporta es especialmente relevante por tres motivos principales, entre otros: uno, porque es la primera después de la realizada en 1972 por el Estudio Preliminar de Transporte de la Región Metropolitana (EPTRM), por lo cual constituye un hito indispensable para la observación de evoluciones. Dos, porque es coincidente con el Censo Nacional de Población, Hogares y Vivienda de 2010. Tres, porque es sincrónica y metodológicamente comparable con las otras nueve ENMODO hechas en otras ciudades argentinas entre 2008 y 2013.

Es en este contexto que se aborda la representación cartográfica de resultados de la ENMODO AMBA 2009-2010 y la consecuente elaboración de un Atlas. El Atlas ENMODO AMBA 2009-2010 (Gutiérrez, 2020) tiene el objetivo de promover la explotación de datos estadísticos oficiales disponibles sobre movilidad urbana, generar información nueva y aportar al corpus de análisis espacial sobre el aglomerado.

En este artículo se recuperan algunos aprendizajes surgidos de los desafíos metodológicos que formaron parte de su elaboración y se presenta la tipología de cartografías de movilidad desarrollada así como los criterios de selección y la estrategia de representación de los mapas que lo componen.

\section{Breve estado de la cuestion}

\subsection{Acerca de las ENMODO y su utilidad}

Las ENMODO son la fuente de información más clásica y útil (Ortúzar y Willumsen, 2007) para conocer las principales tendencias de comportamiento de los viajes (Chapleau y Morency, 2005; Stopher 1996; Stopher, 2009) o patrones de movilidad de una ciudad o aglomerado urbano en su conjunto (tanto en términos territoriales como de los modos y motivos de transporte) y esto con criterios de representatividad estadística, es decir, admitiendo que la información recogida por su intermedio pueda ser expandida al total de la población.

Por esta utilidad, las ENMODO fueron y siguen siendo la principal fuente de información de los procesos de planificación del transporte, resultando indispensables tanto para la toma de decisiones 
en lo sectorial como para la gestión del territorio y de las políticas públicas que en él se despliegan. Concomitantemente, también resultan indispensables en tanto fuente de información oficial y pública sobre movilidad cotidiana, tanto para la gestión como para los estudios del campo en general.

Si bien las nuevas tecnologías permiten hoy relevar información sobre la movilidad cotidiana de los aglomerados urbanos derivables de datos provenientes de la telefonía celular o de las tarjetas electrónicas para el pago de transportes -entre otras fuentes- la representatividad estadística de las ENMODO es insustituible. También su cobertura analítica en cuanto a movilidad y transportes. Y su carácter oficial y público.

Algunos trabajos recuperados en Gutiérrez Puebla et al. (2019) muestran que mediante el uso de datos de la telefonía móvil -cuya unidad de análisis son las personas clientes de las empresas prestadorases limitada la recuperación directa de información respecto de las características sociodemográficas de las personas usuarias y sus hogares así como de los modos de transporte y los motivos de viajes. También se señala la dificultad para reconstruir los trayectos más cortos debido a limitaciones de las antenas, infraestructura a través de la cual se generan los datos que permiten capturar los movimientos de los clientes e interpretarlos como desplazamientos. Por parte de los datos provenientes de las tarjetas electrónicas para el pago de transportes, éstos poseen como unidad de análisis a los viajes realizados y a las personas, pero son una muestra parcial respecto de los patrones de movilidad cotidiana de los aglomerados urbanos que generalmente implican el uso diario de diversos modos de transporte (y también la caminata).

Una ventaja compartida y distintiva de las nuevas fuentes de información que son parte del paradigma del Big Data, es el uso y la velocidad de procesamiento de grandes volúmenes de datos para la generación de conocimiento, a priori, en tiempo real y a un menor costo. Sin embargo su aplicación no es automática e implica desafíos en cuanto al acceso a los datos masivos, desde aquellos vinculados con su propiedad (de empresas particulares) como con su tratamiento y análisis e interpretación (Malvicino \& Yoguel, 2015; Yankelevich et al., 2016) procesos que implican la disponibilidad de software y equipos así como de conocimiento experto multidisciplinario.

Esta sintética comparación permite entrever tanto la singular utilidad de las ENMODO para conocer el contexto general de la movilidad urbana como la relevancia de la complementariedad entre las diversas fuentes de datos (Anapolsky, 2017; Anapolsky, 2020), ya sean cuantitativas convencionales o provenientes del Big Data como información de perfil cualitativo, abriendo un panorama de integración metodológica que, junto con la variable espacial, presentan un potencial analítico diferencial para el campo de estudio del transporte y la movilidad cotidiana (Ksiżkiewicz, 2012; Gutiérrez, 2017).

Respecto a la variable espacial, tanto las ENMODO como las fuentes asociadas a las nuevas tecnologías generan información georreferenciable y por lo tanto suponen un valor -aunque diferente- en relación a su potencial factibilidad para el análisis espacial de la movilidad cotidiana y para el desarrollo de cartografía.

Seguidamente se da cuenta de un breve panorama con respecto a la evolución reciente de las ENMODO y el uso de la cartografía.

\subsection{Acerca de las ENMODO y el uso de cartografía}

El uso principal de las ENMODO -conforme con su utilidad- fue y sigue siendo como herramienta para la planificación del transporte urbano. Dado que posibilitan la alimentación de modelos de demanda de tipo analítico y predictivo (Stopher, 1996), su uso desde la gestión se orienta sobre todo hacia lo prospectivo o proyectual de largo plazo; más que al diagnóstico, la evaluación o la producción de conocimiento sobre los desplazamientos y modos de vida (Dureau et al., 2021), aplicándose en particular al diseño, dimensionamiento y desarrollo de proyectos de infraestructura (Gutiérrez \& Pereyra, 2019). Esto no obstante la existencia de limitaciones presentadas por la modelización (Herce, 2009) así como de críticas formuladas desde países en desarrollo respecto de sus aspectos técnicos, estratégicos, políticos e ideológicos (Vasconcellos, 2015) con potenciales consecuencias sociales y económicas negativas.

Precisando sobre el tipo de dato espacial, las ENMODO generan datos cuantitativos sobre cómo, cuánto, cuándo y por qué motivos se mueve la población del área de estudio. El cómo refiere tanto al modo de transporte como a los orígenes y destino de cada viaje realizado generando información geográficamente referenciable: de dónde a dónde se mueven las personas. Esta última es una pregunta central a la que responden las ENMODO, así como también otras modalidades de la misma familia de encuestas de OrigenDestino, razón por la cual las ENMODO suelen ser conocidas también con esta denominación, siendo su particularidad el carácter presencial y domiciliario (Richardson et al., 1995; Stopher, 2009). 
Dado el gran volumen de personas encuestado en forma presencial y en el domicilio de cada vivienda -y hogares que allí residan - seleccionada por la muestra, son estudios caros que demandan un importante trabajo metodológico y de relevamiento de campo que impactan en la necesidad de un equipo de campo compuesto por un amplio equipo, plazos de ejecución relativamente extensos -que pueden rondar entre los 6 y 12 meses- (Anapolsky, 2017) y en su periodicidad, la cual suele ligarse a los censos de población (Herce, 2009).

Siendo las ENMODO una fuente oficial y pública de información, en países como Argentina y otros de América Latina, estas características se asocian con dificultades para su realización, dando lugar a discontinuidades y vacíos temporales de información sumamente significativos (Pizarro, 2013). En el AMBA, como se mencionó, la ENMODO antecedente a la de 2009-2010 es de 1972. A nivel regional se registra una discontinuidad de los relevamientos entre la década del 70 y el comienzo de este milenio.

Si bien las nuevas tecnologías están haciendo factibles relevamientos virtuales, las encuestas presenciales (en lápiz y papel) aún continúan siendo el pilar de las encuestas a hogares en muchas partes del mundo (Stopher, 2009). En América Latina, la ciudad de Recife (Brasil) implementa la modalidad de encuesta virtual y auto administrada en 2015, sosteniendo desde entonces una periodicidad bianual, a diferencia de lo sucedido con las ENMODO realizadas en 1972 y en 1997, con 25 años de por medio.

Tabla 1. ENMODO identificadas por país, según año de realización del relevamiento.

\begin{tabular}{|c|c|}
\hline País & Área de estudio \\
\hline Argentina & $\begin{array}{l}\text { Área Metropolitana (AM) de Rosario } 2002 \text { y 2008; AM de Córdoba, 2009; AM de } \\
\text { Mendoza, 2010; AM de Posadas, 2010; AM de Tucumán, 2011; AM de Salta, 2012; } \\
\text { Neuquén-Cipolletti, 2012; AM Santa Fe-Paraná, 2012-2013; AM Corrientes-Resistencia, } \\
\text { 2012-2013; AMBA 2009-2010, } 2014 \text { y 2018. }\end{array}$ \\
\hline Brasil & $\begin{array}{l}\text { Región Metropolitana (RM) de Sao Paulo, 1987, 1997, } 2007 \text { y 2017; RM de Río de Janeiro } \\
\text { 2002-2003; RM de Recife 2015-2016 y 2017-2018; RM de Feira de Santana, 2014; RM } \\
\text { de Florianopolis, 2014; RM do Vale Paríba e Litoral Norte, 2014; Brasilia, 2016; RM de } \\
\text { Campinas, 2011; RM de Salvador, } 2011\end{array}$ \\
\hline Chile & Gran Santiago de Chile, 1991, 2001, 2006 y 2012 \\
\hline Colombia & Bogotá 2005, 2011, 2015 y 2019; AM del Valle de Aburrá, 2005, 2012 y 2017; Pereira, 2017 \\
\hline México & Cualiacán, 2015; Zona Metropolitana del Valle de México (ZMVM), 2007, 2015 y 2017 \\
\hline Panamá & AM de Panamá, 2006 \\
\hline Uruguay & AM de Montevideo, 2009 y 2016 \\
\hline Venezuela & Distrito Metropolitano de Caracas, 2006 \\
\hline
\end{tabular}

Fuente: elaboración propia con base en Dureau et al., 2021; Hurtado \& Escalante, 2018; Mauttone \& Hernández, 2017; Subsecretaría de Transportes, s.f; Vasconcellos \& Mendonça, 2016.

Tal como sintetiza la Tabla 1, a partir de los años 2000 el número ciudades de América Latina que realizan ENMODO crece y también aumenta su frecuencia, observándose cierta continuidad desde entonces. Varios países -entre ellos Argentina- ampliaron la cobertura territorial de estos relevamientos llevándolos adelante en varios aglomerados urbanos del país, e incluso algunos se actualizaron en más de una oportunidad en estos últimos años.

En Argentina, en el marco del Proyecto de Transporte Urbano para Áreas Metropolitanas Argentinas (PTUMA) de la ex Secretaria de Transporte de la Nación (actual Ministerio de Transporte), se efectuaron de manera oficial un total de 10 ENMODO en aglomerados urbanos del país entre 2008 y 2013, marcando un hito histórico en relación con la generación de información sectorial a nivel federal (Gutiérrez \& Pereyra, 2019). El AMBA, área que concentra el 33\% de la población del país (INDEC, 2010) ya cuenta con tres relevamientos $^{1}$ : el del mencionado período (año 2009-2010), otro en 2014 (con resultados disponibles públicamente en agosto de 2019) y un tercero en 2018 (aún sin resultados públicamente disponibles).

La generación de información estadística oficial sobre transporte y movilidad cotidiana y transporte a través de las ENMODO aporta así un banco de datos previamente faltantes, a nivel nacional y regional.

Sin pretensión de interpretar las razones de este cambio en cuanto a la disponibilidad de relevamientos tanto a nivel nacional como regional con anterioridad y posterioridad a los años 2000, cabe mencionar como encuadre la consolidación internacional de un marco de políticas en materia de transporte y movilidad cotidiana orientado al control de la expansión urbana y de la motorización y a priorizar el transporte público (Moscoso et al., 2020). Marco asociado a nivel regional y nacional con acciones de fortalecimiento de la planificación del transporte urbano -entre ellas, las ENMODO- con financiamiento

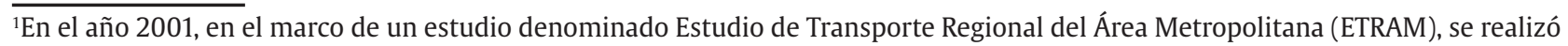
una encuesta de origen-destino para el AMBA que resultó fallida (Terrile, 2021). 
de organismos y bancos internacionales, y en línea con un enfoque a nivel global de políticas basadas en evidencia, atento a diagnosticar, monitorear y evaluar objetivos y metas de política, tales como los 17 Objetivos de Desarrollo Sustentable (ODS). La creación del Observatorio de la Movilidad Urbana de la CAF-Banco de Desarrollo de América Latina surgido en 2010 y fuertemente sustentado en las ENMODO, da cuentas de esto.

Ahora bien, en un mundo donde los sistemas de información geográfica son el corazón de la cuarta revolución tecnológica, la actual disponibilidad y continuidad de estos relevamientos acompañados del sostenimiento de su utilidad (incluyendo su complementación con información de las nuevas tecnologías), hacen esperable un ascenso en la explotación cartográfica de las ENMODO. Sin embargo, se constata un déficit en la elaboración de cartografía a partir de sus resultados.

Las publicaciones de resultados de las ENMODO recientemente efectuadas tanto en Argentina como en Latinoamérica ofrecen información estadística representada en forma de gráficos o tablas, en su totalidad o en parte mayoritaria. La cartografía ofrecida apunta en general a representar las jurisdicciones político-administrativas que componen el área de estudio o bien la zonificación muestral. En cuanto a la representación de los resultados obtenidos mediante la encuesta, la elaboración de cartografía es marginal, especialmente considerando las potencialidades de la información. En contadas ocasiones se incluye cartografía sobre los orígenes y destinos de los flujos generales, tal el caso de Rosario en Argentina (Secretaría de Transporte, 2011a), Montevideo en Uruguay (Mauttone \& Hernández, 2017), Bogotá en Colombia (Secretaría Distrital de Movilidad, 2015; Secretaría Distrital de Movilidad, 2019) (ver Figuras 1 y 2) o en Santiago de Chile (Subsecretaría de Transportes, s.f). Esto se observa también en Montreal (Chapleau \& Morency, 2005) en América del Norte o incluso en países como España (Generalitat de Catalunya, 2006) y Francia en Europa, con una larga tradición y continuidad en la realización de ENMODO y con un acervo en análisis espacial de datos en transporte y movilidad, innovador y de alto nivel.

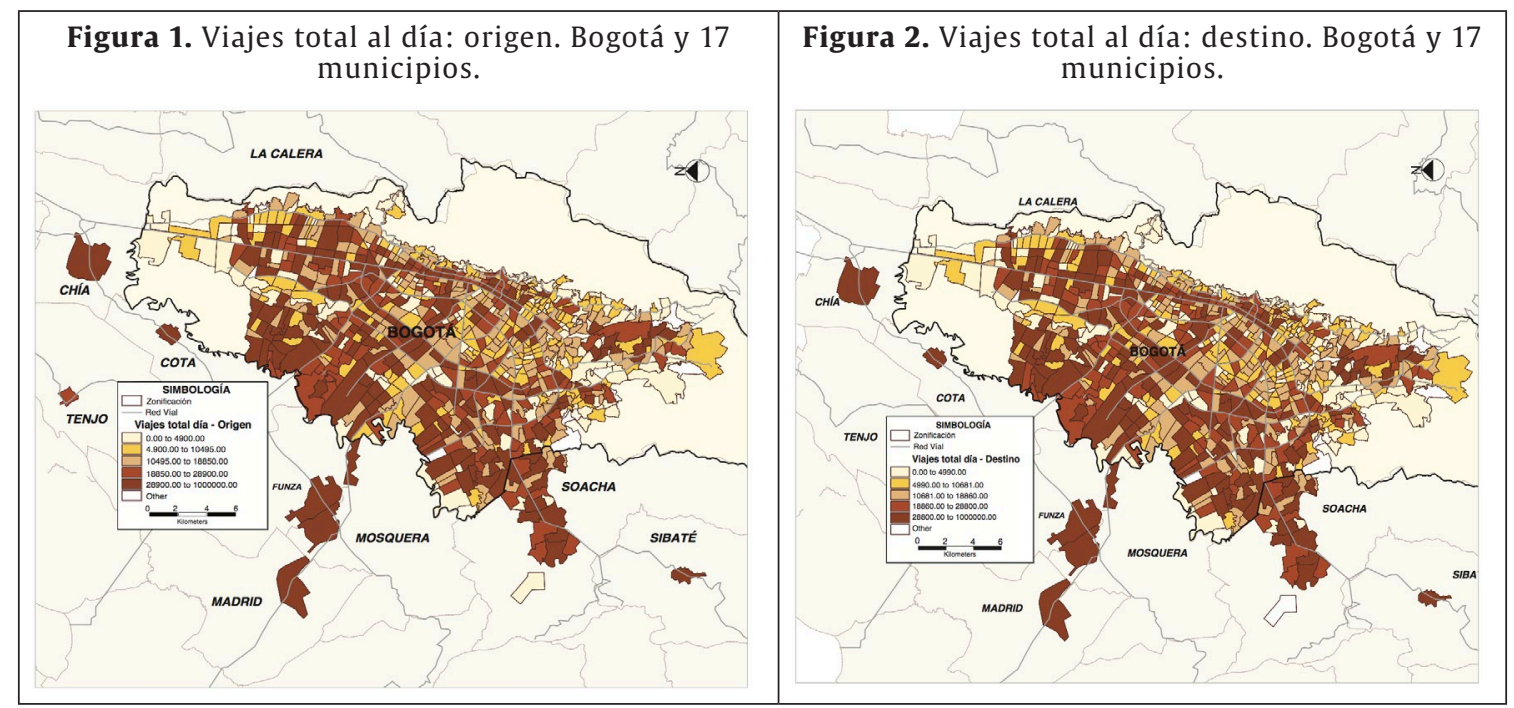

Fuente: Secretaría Distrital de Movilidad, 2015.

Así, los avances en cuanto a la producción de información estadística oficial sobre transporte y movilidad cotidiana a través de las ENMODO son acompañados por un lento desarrollo en la producción de cartografía, y más bien de perfil descriptivo que analítico. Esta brecha entre la utilidad y disponibilidad de la información y su uso para cartografía, amerita ser explorada. La insuficiente explotación de las bases de datos de las ENMODO para elaborar cartografía que facilite el análisis espacial y la observación y de sus resultados, coadyuva a que su utilidad quede circunscrita a un ámbito técnico.

Por fuera de las publicaciones que acompañan la presentación de resultados de las ENMODO, se identifican experiencias recientes que generan cartografías con un sentido más analítico a partir de los datos de las ENMODO. Los estudios sobre caminabilidad desarrollados en Francia por el Centre d'études et d'expertise sur les risques, l'environnement, la mobilité et l'aménagement (CEREMA) (el nombre puede ser traducido como Centro de Estudios y Especialización en Riesgos, Ambiente, Movilidad y Urbanismo) incluyen cartografía de esta índole, vinculada con preguntas relativas al modelo urbano y de movilidad, como por ejemplo aquellas sobre la accesibilidad y la proximidad, ejes del debate actual con respecto a la expansión o compactación de las ciudades. Asimismo, la elaboración de cartografía sobre duraciones de viaje (con estos datos u otros cuantitativos, a escala macro o metropolitana) es frecuente también en Francia y EEUU, pero menos en América Latina y aún menos en Argentina. Al respecto destaca especialmente 
el uso de la ENMODO AMBA 2009-2010 para cartografiar la duración de viajes al trabajo hecha por Yomal (2017) (ver Figura 3). Se observa un incipiente impulso académico a nivel regional de cartografías comparativas -de tipo zonal-realizadas con las últimas ENMODO de Lima y Bogotá (Proyecto MODURAL, 2021), así como de las zonas de origen y destino de los viajes de las trabajadoras domésticas residentes en Bogotá (Montoya, 2020). A nivel nacional se identifican publicaciones recientes que utilizan a las ENMODO aunque no incluyen la representación cartográfica de su información (Arce et al., 2015; Dmuchowsky \& Velázquez, 2017; Neri et al., 2019; Arévalo y De Grande, 2021).

Figura 3. Mapa de zonas.

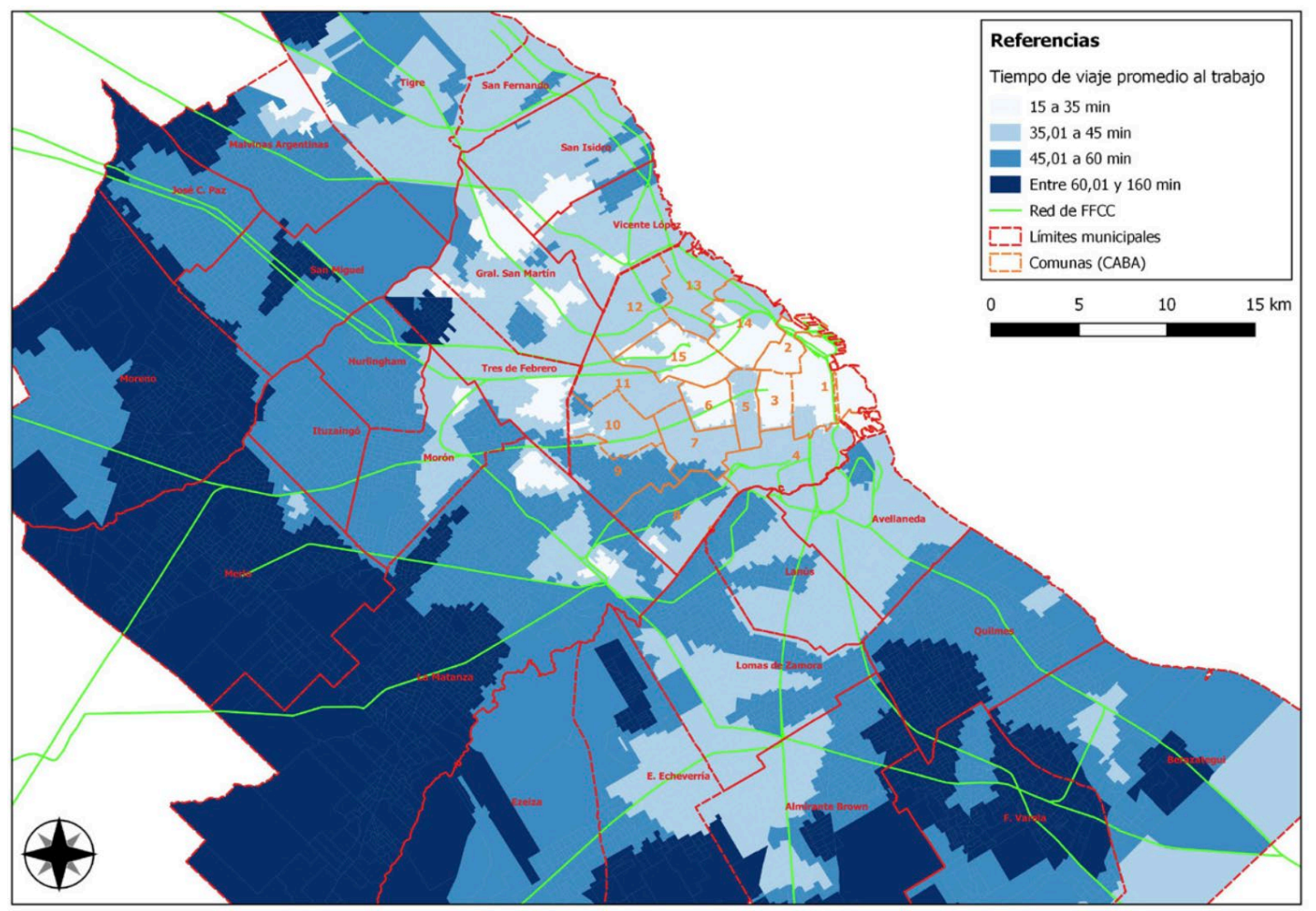

Fuente: Yomal, 2017.

En síntesis, las particularidades de las ENMODO, tanto por el tipo de información producida y su significación para diagnósticos, análisis y tomas de decisiones como por la complejidad de estos relevamientos, hacen que continúen siendo un 'bien preciado' para la gestión del territorio. Fortalecer la elaboración de cartografía por su intermedio contribuye, además, a la generación de capacidades y al acceso a la información (presentes en los ODS).

Es claro que el tratamiento espacial y la georreferenciación de la información estadística contenida en las bases de las ENMODO implican un uso con cierta complejidad. La disponibilidad y continuidad de estos relevamientos oficiales así como sus nuevas formas más flexibles de ejecución, ameritan indagar con más profundidad en los aspectos metodológicos implicados por el tratamiento de los datos en cuanto al análisis espacial y por la información a generar por su intermedio para la elaboración de cartografía. Es por ello que se aborda como estudio de caso a la ENMODO AMBA, a través de la producción de un Atlas, como aporte empírico acerca de la factibilidad metodológica para la representación cartográfica de los datos.

\section{Aspectos metodologicos: el caso de la ENMODO amba 2009-2010}

\subsection{Aspectos generales}

Resulta útil recuperar inicialmente y de manera sintética algunas características metodológicas generales de las ENMODO que son pertinentes para el tratamiento de los datos estadísticos y la interpretación de sus resultados, precisando en aquellas del estudio de caso.

Como se dijo, las ENMODO son encuestas especializadas, mayormente presenciales y domiciliarias, siendo este el caso de la ENMODO AMBA 2009-2010. 
Las ENMODO utilizan formularios estandarizados que recolectan información sobre el hogar, sobre las características socioeconómicas y demográficas de sus miembros y sobre los viajes realizados (y las etapas que los integran) por cada uno de aquellos viajeros mayores a un umbral de edad (por ejemplo: 3 ó 4 años) durante el día hábil inmediatamente anterior al de la encuesta, el cual se constituye como período de referencia. Algunas ENMODO toman también días inhábiles, pero no son la generalidad.

La ENMODO AMBA 2009-2010 establece la encuesta en días hábiles. No se relevaron los viajes realizados por las personas los días sábados, domingos y feriados. Y si bien se encuestó a cada integrante del hogar mayor de 3 años, se consideró como informante directo a las personas de 11 años y más. La información referida a menores de 10 años o quienes estuvieran imposibilitados de comunicarse oralmente, fue recogida mediante un informante idóneo, también integrante del hogar. La definición de viaje contempla a todas aquellos desplazamientos físicos mayores a dos cuadras (200 metros) y que se realizan por un motivo o actividad determinada entre un origen y destino.

El formulario se organiza por módulos: hogares, miembros del hogar, viajes y etapas. Además de contener las preguntas, también incluye las respectivas categorías de respuesta codificadas. En el caso de la ENMODO AMBA 2009-2010, en el módulo referido a viajes prevalece el uso de los indicadores de manera directa para preguntas claves como 'actividad de origen/destino' o ‘duración total del viaje', con sus respectivas categorías de respuesta pero sin incluir la redacción detallada de preguntas. Lo que va en línea con lo señalado por Stopher (2009) respecto de que en ocasiones los instrumentos para la recolección de datos sobre movilidad eran diseñados por especialistas con poca o ninguna formación específica en técnicas de encuesta.

En conformidad a la estructura de su formulario, y luego de aplicados los procesos de depuración y validación de los datos recolectados, éstos pasan a componer bases de datos. Por lo general se componen cuatro bases de datos relacionadas, con datos referidos: (i) al hogar, (ii) a cada una de las personas o miembros que lo componen, (ii) a los viajes diarios (iv) y a las respectivas etapas de viaje realizadas. La Tabla 2 sintetiza la información que contiene cada una de las bases de microdatos públicos de la ENMODO 2009-2010, la cual difiere levemente respecto de las preguntas que componen el formulario puesto que se descartan algunas variables de identificación del hogar (a fin de anonimizarla) y de control del trabajo de campo, y se agregan algunas variables relevantes para su operación y análisis. Se destaca en particular un aspecto que se retoma seguidamente, y es que las bases públicas no inclyen la calle y altura de los orígenes y destinos de los viajes, información clave para el trabajo de geoposicionamiento por coordenadas.

Tabla 2. Síntesis de la información contenida en las bases públicas de la ENMODO 2009-2010.

\begin{tabular}{|c|c|}
\hline $\begin{array}{c}\text { Base } \\
\text { ENMODO } \\
\text { 2009-2010 }\end{array}$ & Información contenida \\
\hline Hogar & $\begin{array}{l}\text { Características de la vivienda: tipo y ubicación, incluyendo partido, localidad, radio y } \\
\text { fracción censal'. } \\
\text { Características propias del hogar, incluyendo ingresos -y la variable creada 'quintil de } \\
\text { ingreso'-, gastos mensuales percibidos y tenencia de vehículos motorizados (automóvil, } \\
\text { motocicleta), no motorizados (bicicleta) y cochera propia. } \\
\text { Incluye también una variable creada que permite identificar a cada hogar en particular } \\
\text { (ID_Hogar), que asimismo funciona como identificador a partir del cual es posible } \\
\text { unificar las cuatro bases o tablas que componen la encuesta. } \\
\text { Incluye además una variable específica para aplicar el Factor de expansión que permite } \\
\text { ponderar la muestra al total poblacional. }\end{array}$ \\
\hline Personas & $\begin{array}{l}\text { Características de cada persona integrante del hogar incluyendo variables } \\
\text { socioeconómicas y demográficas; y solo sobre aquellos mayores de } 14 \text { años también se } \\
\text { incluye información sobre su inserción laboral y variables que permiten distinguir a las } \\
\text { personas que realizaron (o no) viajes así como la razón de no viaje. } \\
\text { Prevé la variable ‘sexo' lo cual hace posible distinguir mujeres y varones. } \\
\text { Cuenta también con variables creadas que permiten identificar a cada hogar en particular } \\
\text { (ID_Hogar) y a cada persona (ID_Persona) y expandir la muestra al total poblacional } \\
\text { (Factor de expansión). }\end{array}$ \\
\hline Viajes & $\begin{array}{l}\text { Características de los viajes realizados por todas las personas mayores de } 3 \text { años } \\
\text { encuestadas incluyendo el origen y destino a nivel partido y localidad, incluyendo } \\
\text { información sobre la actividad realizada en origen y destino -y la variable creada } \\
\text { 'motivo de viaje'-, frecuencia y duración del viaje. } \\
\text { Incluye además las variables creadas que permiten identificar a cada hogar en } \\
\text { particular (ID_Hogar), a cada persona (ID_Persona) y cada viaje (ID_Viaje). También se } \\
\text { incluye el Factor de expansión. }\end{array}$ \\
\hline
\end{tabular}

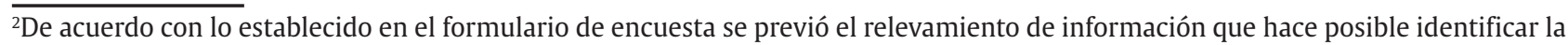
calle y altura de cada vivienda en particular. No obstante, esta información se elimina en la base de datos pública a fin de anonimizar la encuesta y dar cumplimiento a la legislación referida a la confidencialidad de la información y el secreto estadístico. 


\begin{tabular}{|c|l|}
\hline \multirow{5}{*}{ Etapas } & $\begin{array}{l}\text { Características de cada modo de transporte (etapa) utilizado por las personas mayores } \\
\text { de } 3 \text { años encuestadas que realizaron viajes, incluyendo duración de la etapa, la cantidad } \\
\text { de cuadras caminadas antes y luego de subir al modo utilizado, el motivo de la caminata } \\
\text { en caso de haber caminado más de } 10 \text { cuadras, la tarifa abonada y el tipo de boleto en } \\
\text { caso de ser etapas en transporte público y el tipo de estacionamiento, su tarifa y el peaje } \\
\text { abonado, en caso de etapas en vehículo motorizado individual. } \\
\text { Incluye las variables creadas que permiten identificar a cada hogar en particular (ID_ } \\
\text { Hogar), a cada persona (ID_Persona), cada viaje (ID_Viaje) y cada etapa de viaje (ID_ } \\
\text { Etapa). También se incluye el Factor de expansión. }\end{array}$ \\
\hline
\end{tabular}

Fuente: elaboración propia con base en Secretaría de Transporte, 2011b.

Si bien las bases de datos pueden ser trabajadas en forma autónoma o vinculada, en ambos casos hay condicionamientos acerca de los enfoques de consulta y la interpretación de resultados. Un enfoque posible es a partir las personas (u hogares), a fin de trazar patrones de viaje (Gutiérrez, 2012) según la composición del hogar, edad, quintil de ingreso, género u ocupación, por ejemplo. Otro es a partir de las etapas o viajes. Retomamos este particular en el siguiente punto.

\subsection{Aspectos relativos al análisis espacial y la representación cartográfica}

La elaboración de las cartografías de movilidad componentes del Atlas conduce a identificar tres aspectos claves para el análisis espacial y la representación cartográfica de una ENMODO. Uno, la delimitación del área de estudio. Dos, el diseño de la muestra de hogares. Tres, la georreferenciación de los datos espaciales.

La delimitación metodológica del área de estudio de una ENMODO es crucial y a la vez compleja, dado que requiere responder a la unidad territorial funcional de la cual dan cuenta los desplazamientos. Esto es, mediante la existencia de contactos 'cara a cara' a través de la movilidad cotidiana de la población de un aglomerado urbano (Kralich, 2016). Esta unidad territorial funcional no suele responder a las delimitaciones con criterios político-administrativos ni tampoco en ocasiones a los criterios estadísticos oficiales. Tal el caso del área de estudio de la ENMODO AMBA 2009-2010, que no coincide plenamente con la definición dada por el Instituto Nacional de Estadísticas y Censos (INDEC) al momento de realización de la encuesta (cuando el Gran Buenos Aires alcanzaba a 24 municipios aglomerados) ni en la actualidad (que alcanza a 30 municipios aglomerados) (INDEC, 2003; INDEC, 2017).

El área de estudio de la ENMODO AMBA 2009-2010 es sui generis (Fernández, 2020), y está compuesta por la Ciudad Autónoma de Buenos Aires (CABA) y 27 municipios del Gran Buenos Aires (INDEC, 2017), a saber: Almirante Brown, Avellaneda, Berazategui, Esteban Echeverría, Ezeiza, Florencio Varela,, Hurlingham, Ituzaingó, José C. Paz, La Matanza, Lanús, Lomas de Zamora, Malvinas Argentinas, Merlo, Moreno, Morón, Quilmes, San Fernando, San Isidro, San Martín, San Miguel, Tigre, Tres de Febrero y Vicente López. Entre los que se adicionan tres de los seis municipios de la Corona III (Escobar, Pilar y Presidente Perón), la más alejada de la CABA, considerados estratégicos por los altos niveles de urbanización reciente.

La delimitación del área de estudio de una ENMODO tiene asimismo vinculación con el diseño de la muestra de hogares, atento a la representatividad estadística de los resultados. En la ENMODO AMBA 20092010, el diseño de la muestra de hogares está basado en la información del censo nacional de población, hogares y vivienda realizado en 2001 y su calibración se realizó conforme a la Encuesta Permanente de Hogares correspondiente al cuarto trimestre de 2009. Ese año el total de hogares del AMBA rondaba los 4 millones y la muestra de la ENMODO es de 22.500 hogares encuestados. El tamaño muestral deja entrever que se adopta el criterio tradicionalmente utilizado por las ENMODO y que, según autores como Stopher (2009), considera una proporción de entre el 1\% y el 3\% de la población total bajo estudio. Otra estrategia usual para este tipo de relevamientos es subdividir el área de estudio en zonas en las que se asume una conducta homogénea en materia de transporte (Arce et al., 2015), pero no es utilizada en este caso.

Lo relevante a retener para el uso cartográfico de una ENMODO, es que el dominio de estimación (estadística) está en vinculación con un 'área' (en lo espacial). En el caso de la ENMODO AMBA 20092010, el dominio de estimación con respecto al cual los resultados de la muestra son estadísticamente representativos, es el área de estudio total (CABA y 27 municipios aglomerados).

Estas menciones metodológicas son clave para el análisis espacial y la representación cartográfica de una ENMODO puesto que el dominio de estimación condiciona la desagregación espacial de los datos a los fines de la representatividad estadística de los resultados. En el caso de la ENMODO 2009-2010 la muestra de hogares es a razón de un hogar cada 150 del aglomerado urbano, lo cual permite contar con una importante cantidad de hogares para cada jurisdicción político-administrativa (CABA y municipios 
aglomerados), aun sin ser previstos en tanto dominios de estimación. La distribución de los hogares efectivos encuestados (sin expandir) muestra que solo los municipios de Presidente Perón y Escobar se ubican en un rango entre los 200 y 400 hogares. Otros 19 municipios poseen entre 401 y 800 hogares, 5 entre 801 y 1200 hogares y 2 más de 2000 hogares encuestados.

La Tabla 3 refleja la cantidad de casos relevados (efectivos) y la cantidad de casos representados por cada base de datos de la ENMODO 2009-2019, conforme a la expansión de la muestra, a partir de un ponderador (o factor de expansión).

Tabla 3. Cantidad de casos ENMODO 2009-2010.

\begin{tabular}{|c|c|c|}
\hline Base de datos & Total Muestra & Total Expandido \\
\hline Hogares & 22.170 & 4.117 .519 \\
\hline Personas & 70.321 & 12.985 .885 \\
\hline Viajes & 102.784 & 19.767 .983 \\
\hline Etapas & 117.784 & 22.414 .766 \\
\hline
\end{tabular}

Fuente: elaboración propia con base en Secretaría de Transporte, 2011b.

La Tabla 3 ilustra en forma cuantitativa un aspecto metodológico de central importancia para la interpretación del análisis espacial de una ENMODO (y eventualmente, para su posterior representación cartográfica), y es que la distribución de los casos de referencia varía conforme a las distintas bases de datos, y que el tratamiento de cada base requiere coherencia con el enfoque de la consulta y la interpretación de los resultados: es distinto preguntarle a la base de viajes por las personas ( $\mathrm{u}$ hogares), que preguntarle a la base de personas por los viajes (o etapas). Por ejemplo, si bien es posible consultarle a la base de viajes sobre cuántos de éstos son realizados por personas del quintil 1 (de menores ingresos), a dónde, cómo, etc., tales respuestas no expresan cuántos viajes hacen las personas del quintil 1, a dónde, cómo, etc. El 'sujeto' de la pregunta cambia el enfoque de la consulta y también implica uno en el total de casos de referencia (Gutiérrez, 2020). Este aspecto puede parecer poco significativo para quienes tienen un conocimiento especializado pero es clave para aquellos que no lo tienen y se aproximan al uso de este tipo de bases de datos.

En lo atinente a la georreferenciación de los datos espaciales sistematizados en las bases, cada viaje tiene un identificador o ID en la Base Viajes (como consigna la № 2 para el caso del AMBA) a través del cual es posible asociar información que está incluida en las otras bases de la encuesta. En términos territoriales, cada viaje se identifica con una calle y altura, localidad y jurisdicción político administrativa (municipio o CABA, en el caso del AMBA) correspondiente al lugar de origen, y lo mismo para el lugar de destino. Para ser cartografiada, esta información debe ser geoposicionada. En bases de datos de gran magnitud como son las de una ENMODO, el geoposicionamiento a nivel de eje de calle y altura, no está al alcance del común de los usuarios en forma individual. Requiere equipamiento, personal, dinero, tiempo. Y en el caso de la ENMODO 2009-2010, de haberse llevado adelante este procedimiento como parte del trabajo realizado por el equipo técnico responsable a nivel gubernamental, como se mencionó previamente, no está disponible como parte de las bases de datos públicas.

Conforme a lo expuesto, el análisis espacial y la representación cartográfica de la ENMODO AMBA 2009-2010 tiene un doble condicionamiento: por un lado, el relativo a la escala espacial de desagregación que admite la representatividad estadística de la muestra de hogares, y por el otro, el relativo a la escala del geoposicionamiento de los orígenes y destinos de los viajes (o de los hogares). Estos condicionamientos derivaron en los desarrollos metodológicos que se presentan seguidamente, explorados mediante la elaboración de las cartografías de movilidad compiladas por el Atlas.

\section{Resultados: el atlas de la encuesta movilidad domiciliaria (ENMODO) AMBA 2009-2010}

\subsection{Aportes metodológicos}

El Atlas ENMODO AMBA 2009-2010 es el resultado del ensayo metodológico orientado a indagar en la factibilidad y posibilidades para la producción de cartografía analítica y temática sobre movilidad cotidiana, basada en la utilización de este tipo de fuente de información. La iniciativa se inscribe en el contexto de la labor de investigación del Programa Transporte y Territorio (PTT) del Instituto de Geografía de la Universidad de Buenos Aires, con una tradición profundamente geográfica en el abordaje del campo de estudio, sostenida a través de sus más de 30 años de vida. 
El Atlas hace una observación geográfica de la ENMODO a través del espacio material, esto es, desde los desplazamientos (o viajes) realizados, que son aquellos registrados y caracterizados por la encuesta (conforme a su origen y destino, modo, motivo, duración, etc.). No hace una lectura desde la subjetividad de las personas (el espacio experiencial) o desde el sistema de transporte (el espacio de las redes), aunque ambos están en estrecha vinculación con la geografía de los desplazamientos realizados, y su interpretación en profundidad requiere considerarlos ${ }^{3}$.

Los condicionamientos metodológicos antes mencionados con respecto al análisis espacial de la ENMODO AMBA 2009-2010, plantean desafíos para la elaboración de cartografía, y en especial para una de tipo no interactivo ${ }^{4}$. Uno principal es la desagregación espacial de la muestra de hogares manteniendo la representatividad estadística. Como se vio, en el caso de la ENMODO AMBA 2009-2010 ésta habilita hacerlo a escala de las jurisdicciones político administrativa componentes del área de estudio, esto es, tomando a cada una de las 28 relevadas como unidades de análisis espacial, tanto para la agrupación estadística de los datos de la ENMODO como para la representación cartográfica de la información.

Adoptar a las jurisdicciones político-administrativas del AMBA como unidades de análisis espacial y de representación cartográfica tiene dos utilidades analíticas primarias: las jurisdicciones políticoadministrativas son la unidad más frecuente de agrupación de las estadísticas oficiales y también son la unidad de gestión para los tomadores de decisiones y hacedores de política pública. Esto facilita la correlación de la cartografía de la ENMODO con otras fuentes oficiales, como el Censo por ejemplo, así como con los análisis a escala macro o metropolitana. Tiene como principal desventaja un bajo nivel de desagregación espacial de la información, principalmente en relación con aquel de los datos espaciales contenidos en las bases de la ENMODO, lo cual es un condicionante significativo para la observación de las variaciones territoriales y para la precisión locacional de los análisis. No obstante, adoptar a las jurisdicciones político administrativas del AMBA(CABA y municipios) como unidades de análisis estadísticamente representativas, hace posible desarrollar por su intermedio una diversidad de metodologías para el tratamiento espacial y la representación cartográfica de las bases de datos con potencial para el uso de la información e incluso para la generación de nueva información tipo dato.

Según Gutiérrez (2020) asumir a las jurisdicciones político administrativas en tanto lugares geográficos -identificables por sus nombres- hace factible analizar un espacio de redes mediante la utilización de un espacio zona. Cartográficamente, un espacio zona permite trabajar con dos tipologías de representación complementarias: mapas de flujos (que representan la vinculación entre zonas como pares de origen-destino de viajes) y mapas de zonas (que representan la distribución entre zonas de los valores referenciados en el territorio). Estadísticamente, un espacio zona permite análisis comparados del espacio de redes mediante la asignación al territorio de tres tipos de valores contenidos en una ENMODO: respectivos a los orígenes y destinos de los viajes, respectivos a las personas y hogares (como lugar de residencia) y respectivos a las actividades (como lugar de actividad).

Este uso metodológico combinado es factible de ser aplicado a distintas unidades de análisis espacial tipo zona (localidades, por ejemplo) en tanto no pierdan su representatividad estadística conforme al diseño muestral de la ENMODO en cuestión. En el caso de la ENMODO AMBA 2009-2010, siendo que la muestra de hogares se mantiene estadísticamente representativa y que las bases de datos contienen información relativa a los viajes y también a las personas y hogares, es factible utilizar a la jurisdicción político administrativa (municipios y CABA) como lugar o referencia geográfica de estos tres modos: para localizar los orígenes y destinos de los viajes, como lugar de residencia (personas y hogares) y como lugar de actividad (estudio, trabajo, salud, por ejemplo).

Aplicando esta combinación metodológica, Gutiérrez (2020) desarrolla la siguiente tipología de cartografías de movilidad:

1) Mapas de flujos:

Representan los pares de origen-destino referenciando a la zona (jurisdicción político administrativa en el caso de la ENMODO AMBA) en tanto lugar de origen o destino del viaje. Estos mapas admiten trabajar con el volumen (o cantidad de viajes) de los flujos y con su dirección, y también con el sentido del viaje (de ida o de regreso) ${ }^{5}$ algo particularmente pertinente para los viajes por motivo de actividad (trabajo, estudio,

\footnotetext{
${ }^{3}$ Estas distinciones hacen parte del marco conceptual que organiza los Proyectos UBACyT con lugar de trabajo en el PTT realizados a partir de 2008 y hasta la actualidad, dirigidos por Andrea Gutiérrez. Respecto a la distinción del universo de viales que balizan el campo de conocimiento de la movilidad territorial ver Gutiérrez (2012).

${ }^{4}$ Las plataformas web de datos espaciales de tipo interactivo habilitan la representación cartográfica de la totalidad de los orígenesdestinos relevados mediante líneas o segmentos individuales, sin limitación de legibilidad (por superposición) de la información respectiva. El uso de cartografía estática convencional, requiere el uso de una cantidad limitada de segmentos, y la consecuente agrupación de la información en rangos de valor.

${ }^{5}$ La dirección de un viaje remite a una posición en el territorio material o lugar geográfico. Los flujos pueden expresar viajes desdehacia o entre lugares. El sentido de un viaje pone al lugar en relación con el viajero, en tanto donante del sentido. Conforme a su
} 
salud, compras, etc., según la codificación resultante del formulario de la encuesta). Siguiendo desarrollos anteriores en cuanto a la utilización de espacios zona para el análisis espacial de la proximidad/distancia (métrica o temporal) (Gutiérrez \& Reyes 2017; Gutiérrez \& Apaolaza, 2018), se distingue la representación de los flujos con origen y destino en distintas zonas de aquellos con origen y destino en la misma zona coadyuvando a interpretar las distancias de manera indirecta (dentro de la jurisdicción, entre jurisdicciones colindantes o no colindantes).

\section{2) Mapas de zonas:}

Representan la distribución territorial de valores referenciándolos a la zona en tanto jurisdicción político administrativa o jurisdicción de residencia. Estos mapas admiten trabajar con el volumen (o cantidad de viajes) -en valores absolutos o porcentuales- pero también con el sentido del viaje (de ida o de regreso). Siguiendo el mismo criterio aplicado a los mapas de flujos, se desarrolla una manera innovadora de expresar la atracción de cada jurisdicción con respecto a una actividad, mediante la representación del volumen o cantidad de viajes de regreso por motivo de actividad (seleccionándolos según la 'actividad de origen' pero referenciándolos geográficamente desde la jurisdicción de destino). Estos mapas de zonas son denominados de generación de viajes dado que habilitan una forma indirecta de interpretar la distribución territorial de las actividades -no sólo en cantidad sino también en calidad- ponderándolas a través de su 'uso'. Los mapas de zonas también permiten trabajar con la noción de proximidad/distancia (métrica y temporal) mediante la representación de valores sobre la duración de los viajes. La distribución territorial resultante habilita visualizar características comparadas de las zonas entre sí (jurisdicciones) y consigo misma, es decir, según la representación de valores por modos de transporte, motivos de actividad, grupo social, etc. Esto es, pueden verse las desventajas (o ventajas) acumulativas o diferenciales (en el territorio) de una zona.

Como se mencionó, esta tipología aplica al uso de un espacio zona -estadísticamente representativo conforme al diseño muestral- como unidad de análisis (espacial y estadística) para la representación cartográfica de las bases de datos de las ENMODO mediante mapas no interactivos. En el caso de la ENMODO AMBA 2009-2010, el uso de la jurisdicción político administrativa (municipios y CABA) como espacio zona y lugar para la georreferencia de la información se muestra factible para la elaboración de cartografías de movilidad. Se presentan seguidamente los aportes empíricos resultantes.

\subsection{Aportes empíricos}

Los mapas componentes del Atlas toman como cartografía de base a la proveniente del Instituto Geográfico Nacional (IGN). La escala, indicada en cada mapa, es 1:227000 y la proyección cartográfica es WGS84. Las cartografías de movilidad elaboradas por su intermedio utilizan el Software QGIS y cuentan con la fiscalización del IGN. Están disponibles para su consulta en línea y descarga gratuita -en formato individual y en formato de libro digital- en el sitio web del Programa Transporte y Territorio del Instituto de Geografía de la Universidad de Buenos Aires (https://transporteterritorio.wixsite.com/pttuba) ${ }^{6}$.

Se utilizan tres simbologías para representar la información cartografiada: (i) segmentos o vectores ( $\sin$ y con orientación de sentido -en forma de flechas-), graduados acorde a la distribución de los valores (ii) círculos (graduados de acuerdo con los valores) y (iii) color (graduado de acuerdo con los valores, del blanco al negro y en gama de grises). La información complementaria proveniente de otras fuentes (universidades y hospitales del sistema público) se grafica mediante iconos en forma de rombos.

No obstante la menor riqueza visual de la paleta de color seleccionada, se considera la ventaja que presenta en tanto admite dos colores (blanco y negro) más la tonalidad de grises. Y en especial se considera la posibilidad de que los mapas (disponibles en la web para su descarga gratuita) puedan ser impresos, atento a lo cual esta gama facilita visualizar la información sin requerir tinta a color. Esto conforme al objetivo de potenciar el uso de la cartografía elaborada por parte de un perfil amplio de interesados, ya sean expertos o decisores de políticas públicas, estudiantes, docentes o público en general.

Una vez observadas las condiciones que hacen al manejo espacial de los datos estadísticos y definido su tratamiento cartográfico conforme a ello (ver punto 3) el abanico de la cartografía temática que habilita la información contenida en una ENMODO es sumamente vasto. La elaboración de un Atlas por su intermedio - en tanto producto en sí mismo- requiere una unidad de sentido propia.

Al respecto, la selección de las cartografías de movilidad elaboradas y compendiadas en el Atlas 
ENMODO AMBA 2009-2010, sigue tres criterios generales. Uno, complementar el núcleo básico de la información contenida en las publicaciones de resultados de las ENMODO ofreciendo su lectura espacial. Dos, renovar o ampliar los análisis clásicos por motivos de viaje o medios de transporte, incluyendo medios o motivos no convencionales Tres, explorar algunas potencialidades de la información contenida en las ENMODO. En algunos casos estas exploraciones están motivadas por vacíos de información (tal el caso del mapa sobre generación de viajes por trabajo, por ejemplo) y en otros por exploraciones conceptuales que hacen al interés de los Proyectos de investigación UBACyT ${ }^{7}$ desarrollados en el marco del PTT (tal el caso del concepto de 'proximidad' desde lo espacio temporal y su vinculación con la desigualdad socioespacial).

Conforme a estos criterios generales y siguiendo las tipologías desarrolladas por Gutiérrez (2020) se elaboran 30 mapas: 14 mapas de flujos y 16 mapas de zonas (4 de volumen, 3 de generación, 6 de duración promedio, 2 de relación entre magnitudes), seleccionando como ejes temáticos al total de viajes, los motivos de viaje, modos de transporte, el género y quintil de ingresos (Tabla 4).

Tabla 4. Cantidad de mapas por eje tipología y eje temático. En absolutos.

\begin{tabular}{|c|c|c|c|c|c|c|}
\hline \multirow{2}{*}{\multicolumn{2}{|c|}{ Tipología }} & \multicolumn{5}{|c|}{ Ejes temáticos } \\
\hline & & Totales & $\begin{array}{c}\text { motivo de } \\
\text { viaje }\end{array}$ & $\begin{array}{l}\text { modo de } \\
\text { transporte }\end{array}$ & género & $\begin{array}{l}\text { quintil de } \\
\text { ingresos }\end{array}$ \\
\hline \multicolumn{2}{|r|}{ FLUJOS } & 1 & 3 & 6 & 2 & 2 \\
\hline \multirow{4}{*}{ ZONAS } & $\begin{array}{c}\text { VOLUMEN } \\
\text { (o CANTIDADES) }\end{array}$ & - & - & 2 & - & 2 \\
\hline & GENERACIÓN & - & 3 & - & - & - \\
\hline & $\begin{array}{l}\text { DURACIÓN } \\
\text { PROMEDIO }\end{array}$ & 1 & 3 & 3 & - & - \\
\hline & $\begin{array}{l}\text { RELACIÓN ENTRE } \\
\text { MAGNITUDES }\end{array}$ & - & - & 1 & 1 & - \\
\hline & TOTAL & 2 & 9 & 12 & 3 & 4 \\
\hline
\end{tabular}

Fuente: elaboración propia

Los mapas según modos de transporte cartografían los viajes por transportes masivos (subterráneo, ferrocarril y autotransporte colectivo), automóvil, transporte no motorizado (en bicicleta y a pie), bus escolar, taxi - remis y chárter - combi - bus empresa. De esta manera, se elabora cartografía para el núcleo básico de la información estadística incluida en la publicación de resultados de la ENMODO AMBA 20092010 y además se desglosa aquella sobre modos de transporte agrupados como 'otros' por su escasa participación respecto al volumen total de viajes, pero que sin embargo es útil observar como insumo para las políticas públicas (como el bus escolar o el charter/combi/ bus empresa) o para la agenda sectorial actual (como el taxi y el remís, cuya participación sufre la mayor variación entre 1970 y 2010, y que hoy entran en competencia con servicios nuevos como UBER, por ejemplo).

Los mapas según motivo de actividad cartografían los viajes por trabajo, estudio y salud, incluyendo las actividades que componen el núcleo básico de la información estadística publicada, y considerando actividades productivas y reproductivas vinculadas con políticas públicas. La ENMODO 2009-2010 permite analizar también otras actividades, entre ellas las compras y el dejar, buscar o acompañar a un miembro del hogar a un centro educativo. Siguiendo el enfoque introducido por Sánchez de Madariaga (2009), que visibiliza la movilidad cotidiana vinculada con la reproducción social, se elabora cartografía con la movilidad por motivos de cuidado, incluyendo conjuntamente a los viajes por estas dos últimas actividades y por motivo salud.

Los mapas con apertura por género se elaboran asumiendo la información disponible, que refiere al sexo de la persona encuestada con dos aperturas (varón y mujer). Los mapas por quintiles de ingreso se elaboran con dos aperturas, representando los viajes de personas residentes en hogares de los quintiles de ingreso más bajo (quintil 1) y más alto (quintil 5).

Con respecto a las tipologías, todos los mapas de flujos trabajan de manera indirecta con la distancia, distinguiendo aquellos flujos con origen y destino en la misma jurisdicción (viajes dentro) o en distintas jurisdicciones (viajes entre). Los mapas de flujos por motivo de actividad seleccionan los viajes de ida conforme a la 'actividad de destino'. Y en el caso de los mapas de zonas, aquellos de volumen por modo de transporte referencian la jurisdicción de origen y/o destino del viaje, apuntando a mostrar la distribución territorial del uso de cada modo, como insumo para la planificación de la oferta. Y los de volumen por quintil de ingreso y por motivo cuidado según género, referencian los viajes según la

${ }^{7}$ Los UBACyT son proyectos de investigación evaluados y financiados la Universidad de Buenos Aires a través de su Secretaría de Ciencia y Técnica. 
jurisdicción de residencia, apuntando a mostrar la distribución territorial de la población. Los mapas de duración también representan aquella promedio por jurisdicción político-administrativa, referenciándolos por jurisdicción de residencia. Y los mapas de generación referencian los viajes de regreso por motivo de actividad (seleccionándolos conforme a la 'actividad de origen', pero referenciándolos desde la jurisdicción de destino). Dado que apuntan a expresar el uso de las actividades en el territorio, los mapas por estudio y salud incluyen la localización de los establecimientos educativos y sanitarios, respectivamente. Los mapas de relación entre magnitudes visualizan la información que deriva de la lectura combinada de dos variables. En el caso de las cartografías componentes del Atlas, entre los viajes por motivos de cuidado y el género; y entre la tasa de hogares con auto y el promedio de autos por hogar.

Si bien todos los mapas generan información a través del análisis espacial de los resultados estadísticos de la ENMODO AMBA 2009-2010 (publicados o contenidos en las bases de datos) se distinguen mapas con un perfil más descriptivo de la información y con un aporte diagnóstico, y mapas elaborados a partir del planteo de una pregunta y con un aporte más analítico, cuya información cartografiada arroja respuestas que a la vez colaboran en generar nuevas preguntas. El mapa de los viajes por motivo trabajo, por ejemplo, es un resultado especialmente importante como diagnóstico, dada la carencia de datos espaciales sobre la distribución territorial del empleo en el AMBA. Los mapas de duración, en tanto, revelan su desigual distribución conforme a distintos modos de transporte y/o motivos de actividad y asimismo su desigual distribución territorial. Esto da lugar a visualizar jurisdicciones que acumulan ventajas/desventajas en los distintos motivos de viaje o modos de transporte, y jurisdicciones con ventajas/desventajas diferenciales (desventajas respecto a los transportes masivos y ventajas respecto al automóvil, por ejemplo). Lo que coadyuva a visualizar e interpretar procesos de segregación y/o fragmentación territorial desde lo espacio temporal (Gutiérrez, 2020).

\section{Las cartografías de movilidad como insumo para la gestión del territorio y las políticas públicas}

Como se mencionó, el objetivo de compendiar en un Atlas las cartografías elaboradas para observar la factibilidad y posibilidades de representar cartográficamente a la ENMODO AMBA 2009-2010, es derivar nueva información de los datos existentes. Si bien esto sucede con cualquier análisis espacial, dado que los mapas invitan inherentemente a la visualización de patrones y a la interpretación de las relaciones espaciales que muestran, cabe recuperar la importancia de atender al desarrollo metodológico de formas de representación cartográfica de los datos ofrecidos por las ENMODO. Estos condicionan su interpretación, y por ende, su utilidad como insumo para políticas públicas. Hacerlo de un modo convencional puede dar lugar a visualizar 'verdades reveladas' -o confirmaciones de lo ya conocido- y hacer ver el aporte analítico de la elaboración de cartografía (y de la fuente de información) como poco interesante, y no muy innovador. Y a su vez estar dejando en la penumbra la emergencia de información relevante.

Atento a ejemplificar las posibilidades que habilita el análisis espacial y cartográfico de los resultados de la ENMODO AMBA 2009-2010 para generar información útil como insumo para la gestión del territorio y para políticas públicas, se interpretan algunos resultados emergentes del mapa básico: el de los flujos totales de viajes del AMBA (Figura 4). 
Figura 4. Mapa de flujos - Viajes Totales.

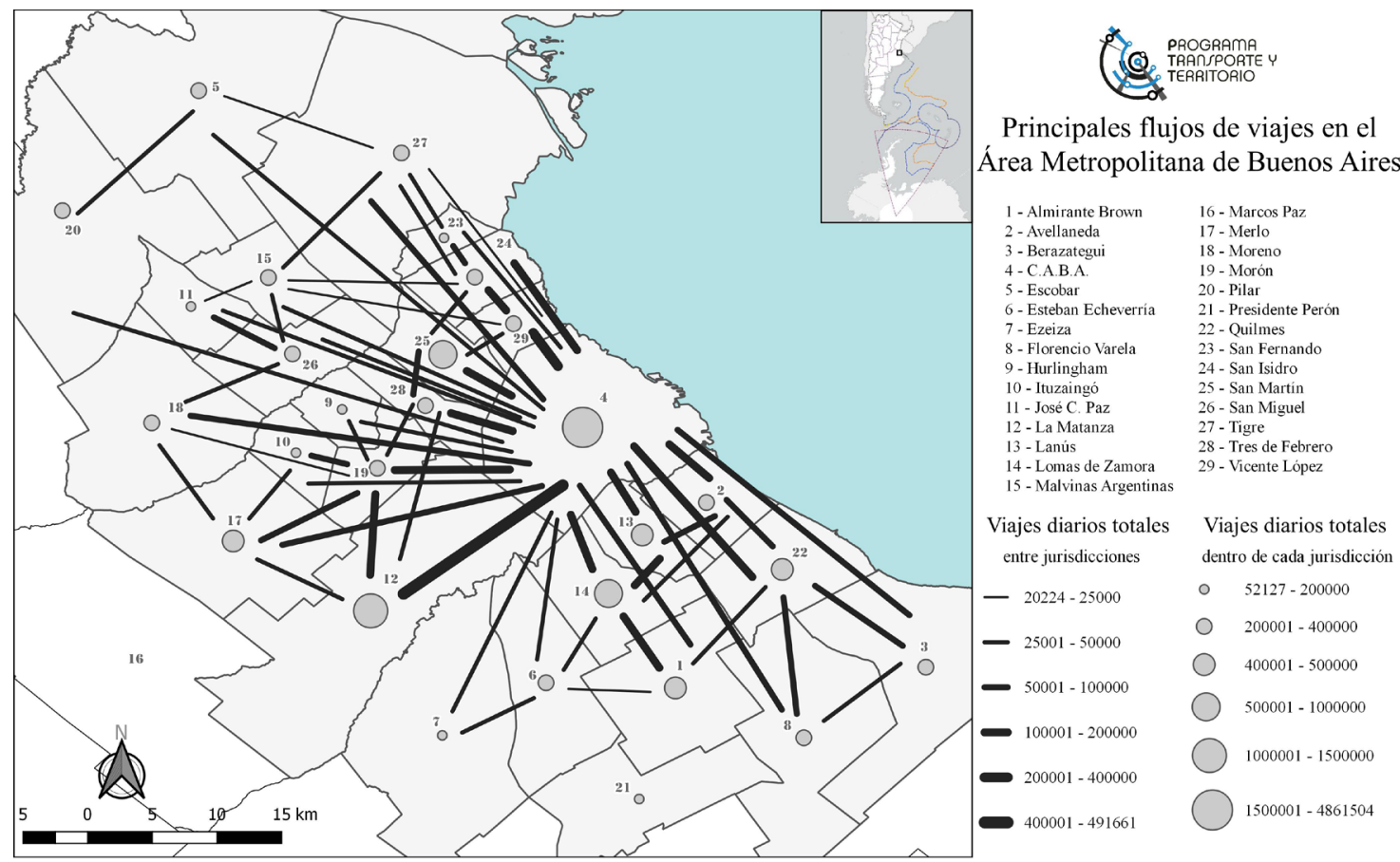

Fuente: elaboración propia con base en Secretaría de Transporte, 2011b.

El mapa de flujos totales representa los viajes entre pares de origen-destino con independencia de su sentido (ida y/o vuelta). La dirección de los flujos entre jurisdicciones muestra la prevalencia de aquellos convergentes a la CABA y valida la vigencia de tendencias radioconcéntricas en el patrón de movilidad metropolitano. Cartografiar los flujos distinguiendo aquellos entre y dentro de las jurisdicciones acompañados de una escala de su volumen facilita una interpretación complementaria: la mayoría de los viajes metropolitanos son dentro de una misma jurisdicción, y su volumen es notablemente superior al de aquellos con la CABA. Esto ilumina y jerarquiza dos focos de atención para la gestión de la movilidad metropolitana.

La propuesta metodológica desarrollada para el geoposicionamiento de los datos de una ENMODO mediante un espacio zona -en el caso de la ENMODO AMBA 2009-2010, la jurisdicción político administrativa- se evidencia satisfactoria para mantener la representación estadística y espacial de la muestra y para habilitar tanto la observación de relaciones de distribución territorial como de relaciones de interacción espacial. Estas relaciones de interacción son fundamentales en el análisis de redes, considerando la configuración de un sistema de localizaciones, las distancias (ideales o reales) y los vínculos o flujos que constituyen espacios funcionales.

Analizar un espacio de redes de manera agregada permite observar a cada jurisdicción como un 'nodo' de la red, y colaborar con la observación de flujos entre jurisdicciones y también dentro de ellas (dentro de cada 'espacio zona'). Esto asimismo habilita el análisis espacio-temporal a través de conceptos como 'dentro y entre' o 'dentro y fuera' (Gutiérrez \& Reyes, 2017), como aproximaciones a la interpretación de distancias, de manera espacialmente agregada (Gutiérrez \& Apaolaza, 2018).

En síntesis, las cartografías de movilidad componentes del Atlas ENMODO AMBA 2009-2010 se presentan como un resultado acerca de la factibilidad y posibilidades para la explotación cartográfica de los datos estadísticos disponibles sobre movilidad cotidiana provenientes de estas fuentes de información, asumiendo los desafíos metodológicos y analíticos aquí desarrollados. Y también como una potencialidad, abriendo la posibilidad de derivar nuevos análisis e interpretaciones a partir de un producto cartográfico.

Identificar las tendencias de la movilidad cotidiana es clave para la gestión territorial urbana. En el contexto actual de la pandemia aplica a cuestiones prácticas como adecuar la oferta de transporte público o posibilitar el rol prioritario y multi-escalar que éste adquiere en la organización social de los cuidados. Las compras, ir o acompañar al médico, llevar a los niños a actividades educativas o de esparcimiento, implican desplazamientos que por un lado destacan la relevancia de la movilidad local y de proximidad, y por el otro evidencian relaciones funcionales entre las jurisdicciones del aglomerado a la hora de asegurar su concreción (para acceder a los servicios de salud o cubrir las tareas de cuidados a través de la contratación de servicios o personal, por ejemplo). Ambas cuestiones son ejemplos que contribuyen a correr el foco de problemas ya visibles en la agenda actual de la gestión y las políticas públicas, como la congestión y el 
uso del automóvil, y traer de la penumbra a otros, como el diseño de la red de autotransporte público y su cobertura, especialmente fuera del área central y entre localidades de la periferia.

\section{Conclusión y reflexiones finales}

Las ENMODO son una fuente de información indispensable e insustituible para la planificación y gestión del transporte y la movilidad. Si bien sus resultados son georreferenciables y susceptibles de análisis espacial así como de representación cartográfica, esta utilidad es subestimada por las publicaciones de resultados de las propias encuestas y por el uso general que se hace de los mimos.

Un hallazgo primario emergente de la elaboración del Atlas es constatar la factibilidad de representar cartográficamente resultados de la ENMODO AMBA 2009-2010. Las tipologías de cartografías de movilidad desarrolladas y los criterios de selección temática ofrecen un aporte tanto en lo metodológico como en información empírica, que aporta al corpus de análisis espacial sobre el aglomerado y son ilustrativas de posibilidades a explorar y ampliar por otros trabajos a futuro.

Atento a interpretar el contraste entre la inédita disponibilidad de información oficial sobre movilidad cotidiana proveniente de estas fuentes de información insustituibles (en el AMBA, en Argentina e incluso en América Latina) y la debilidad de la producción cartográfica existente en un contexto de auge de las herramientas para el tratamiento de datos espaciales; una primera observación derivada de la elaboración del Atlas es que los desarrollos metodológicos requeridos para el caso de la ENMODO AMBA 2009-2010 señalan la importancia de identificar y problematizar el tratamiento de las bases de datos de las ENMODO en vistas a generar conocimiento que facilite y mejore su explotación. Este requerimiento, en sí mismo, puede contribuir a interpretar la brecha entre la disponibilidad de información y el déficit de cartografía.

Una segunda observación derivada de la elaboración del Atlas y de constatar la factibilidad de producir cartografías de movilidad por intermedio de una ENMODO, es que tales desarrollos son útiles para promover el acceso a información oficial y pública sobre movilidad cotidiana de un público amplio, usuario de esta información y no necesariamente experto, aplicando esto a técnicos, decisores, académicos, estudiantes, la ciudadanía en general.

En un contexto nacional e internacional de políticas públicas basadas en evidencia, promover el acceso a información oficial sobre movilidad cotidiana contribuye al logro de Objetivos de Desarrollo Sostenible en forma transversal y más allá del específico vinculado a las ciudades y comunidades, tales como fortalecer capacidades y fomentar la participación ciudadana y la igualdad de género, promoviendo la derivación a futuro de nueva información a partir del uso de la cartografía por parte un perfil ampliado de interesados en la temática.

Finalmente, la elaboración del Atlas en tanto propuesta de representación cartográfica de los datos obtenidos a través de la ENMODO AMBA 2009-2010, espera contribuir a renovar el modo de interpelar a este tipo de encuestas, haciendo una lectura atenta y cuidadosa en lo espacial. Explotar la información que contienen ayuda a destacar la importancia que la perspectiva territorial tiene para analizar los desplazamientos de la población (en este caso de la movilidad cotidiana, aunque aplica a otras movilidades), y a recuperar, como plantea Cresswell (2006), que la movilidad es tan espacial -como geográfica- y tan central para la experiencia humana del mundo, como el lugar. Las cartografías de movilidad son una herramienta para planteos y acciones que tiendan a superar la fragmentación sectorial de las políticas públicas en la gestión del territorio.

\section{Referencias bibliográficas}

Anapolsky, S. (2017). Encuestas de Origen y Destino en A. Gutiérrez (Coord.), Manual sobre metodologías de estudio aplicables a la planificación y gestión del transporte y la movilidad: recomendaciones sobre el uso de herramientas cuali-cuantitativas de base territorial (pp. 17-24). Eudeba.

Anapolsky, S. (2020). ¿Cómo nos movemos en el AMBA?. Conclusiones de la evidencia empírica y alternativas post-Covid. Serie: Documentos de Trabajo del Instituto del Transporte №18, Universidad Nacional de San Martín. https://www.unsam.edu.ar/institutos/transporte/publicaciones/Documento\%2018\%20 Comonos\%20movemos\%20en\%20el\%20AMBA\%20-\%20Anapolsky.pdf

Arce, G. López, S. y Rey, C. (2015). Encuestas de movilidad domiciliaria: Revisión bajo perspectivas de la movilidad y aplicación en las áreas metropolitanas de Resistencia y Corrientes, Argentina. Revista Ingeniería de Transporte, 19, 37-53. http://repositorio.unne.edu.ar/handle/123456789/28010 
Arévalo, C. y De Grande, P. (2021). Infancias y autonomías: condicionantes de la movilidad independiente en el Área Metropolitana de Buenos Aires. Revista Densidades, 30, 104-123. http://desidades.ufrj. br/featured_topic/infancias-y-autonomias-condicionantes-de-la-movilidad-independiente-en-elarea-metropolitana-de-buenos-aires/

Chapleau, R.; Morency, C. (2005). Dynamic spatial analysis of urban travel survey data using GIS. [Presentación de ponencia]. 25th Annual ESRI International User Conference, San Diego, Estados Unidos. https://proceedings.esri.com/library/userconf/proc05/abstracts/a1232.html

Cresswell, T. (2006). On the Move. Mobility in the modern western word. Routledge.

Dmuchowsky, J. y Velázquez, M. (2017). Movilidad urbana y reparto modal en las ciudades metropolitanas de la Argentina en A. Müller (Comp.), Transporte urbano e interurbano en la Argentina: aportes desde la investigación (pp. 25-40). Eudeba.

Dureau, F., Giroud, M., y Lévy, J. (2021). La observación de las movilidades cotidianas. Revista INVI, 36(102), 208-259. https://doi.org/10.4067/S0718-83582021000200208

Fernández, L. (2020) Región, regionalización y conurbación de Buenos Aires. Café de las Ciudades. https://cafedelasciudades.com.ar/sitio/contenidos/ver/366/que-es-el-amba-iii-y-ultima-regionregionalizacion-y-conurbacion-de-buenos-aires.html

Generalitat de Catalunya (2006). Enquesta de Mobilitat Quotidiana de Catalunya. Autoritat del Transport Metropolitá. https://territori.gencat.cat/web/.content/home/01_departament/documentacio/ territori_mobilitat/transport_public/documentacio_tecnica/enquesta_de_mobilitat_quotidiana_ de_catalunya_2006/pdf/principals_resultats_emq_2006_juny_tcm32-39950.pdf

Gutiérrez, A. (2020). Cartografías de movilidad. Atlas de la Encuesta de Movilidad Domiciliaria del Área Metropolitana de Buenos Aires 2009-2010. El guión Ediciones. https://transporteterritorio.wixsite. com/pttuba/publicaciones-1?lightbox=dataItem-kqhbyhve

Gutiérrez, A. (Coord.) (2017). Manual sobre metodologías de estudio aplicables a la planificación y gestión del transporte y la movilidad: recomendaciones sobre el uso de herramientas cuali-cuantitativas de base territorial. Eudeba.

Gutiérrez, A. (2012). ¿Qué es la movilidad?. Revista Bitácora Urbano Territorial, 21(2), 61-74. http://www. redalyc.org/articulo.oa?id=74826255011

Gutiérrez, A y Pereyra, L. (2019). La movilidad cotidiana en ciudades argentinas. Un análisis comparado con enfoque de género. Lavboratorio, Revista de Estudios sobre Cambio Estructural y Desigualdad Social, 29, 143-166. https://publicaciones.sociales.uba.ar/index.php/lavboratorio/article/view/5126

Gutiérrez, A y Apaolaza, R. (2018). Segregación socioespacial y periferias urbanas. Análisis del entorno territorial de los nuevos asentamientos informales de la Región Metropolitana de Buenos Aires a partir de la utilización de micro datos censales y de transporte. En Hacia la metamorfosis urbana: apuntes latinoamericanos para una política urbana. (pp. 43-71). Universidad Privada Boliviana CIAU-SEUR.

Gutiérrez, A y Reyes, M. (2017). Mujeres entre la libertad y la obligación. Prácticas de movilidad cotidiana en el Gran Buenos Aires. Revista Transporte y Territorio, 16, 147-166. https://doi.org/10.34096/rtt. $\underline{\mathrm{i} 16.3607}$

Gutiérrez Puebla, J., Benítez, C., Leaño, J., García Palomares, J., Condeço Melhorado, A., Mojica, C., Scholl, L., Adler, V., Vera, F., Moya Gómez, B., and Romanillos Arroyo, G. (2019). Cómo aplicar big data en la planificación del transporte urbano: El uso de datos de telefonía móvil en el análisis de la movilidad. Banco Interamericano de Desarrollo, Nota técnica nำ IDB-TN-1773. https://publications.iadb.org/es/ como-aplicar-big-data-en-la-planificacion-del-transporte-urbano-el-uso-de-datos-de-telefoniamovil.

Herce, M. (2009). Sobre la movilidad en la ciudad. Editorial Reverte.

Hurtado, V; Escalante, D. (Septiembre, 2018). Planeación y aprovechamiento de las EOD (Encuesta OrigenDestino). [Webinar]. WRI México y The City Fix Learn. https://thecityfixlearn.org/sites/default/ files/13.\%20WEBINAR\%20Serie\%20EstudiosOrigen\%20Destino\%201\%20Introduccio\%CC\%81n.pdf

INDEC (2003). ¿Qué es el Gran Buenos Aires?. Buenos Aires: Instituto Nacional de Estadística y Censos. https://www.indec.gob.ar/dbindec/folleto_gba.pdf

INDEC (2010). Censo Nacional de Población, Hogares y Vivienda. Buenos Aires: Instituto Nacional de Estadística y Censos. https://www.indec.gob.ar/indec/web/Nivel3-Tema-2-41 
INDEC (2017). Anuario estadístico de la República Argentina 2015, 1ra. Edición, Buenos Aires: Instituto Nacional de Estadística y Censos. https://www.indec.gob.ar/ftp/cuadros/sociedad/Anuario_ Estadistico_2015.pdf

Kralich, S. (2016) Urbanización y transporte. Algunos aportes conceptuales. Revista Transporte y Territorio, 15, 41-67. https://doi.org/10.34096/rtt.i15.2848 ARTIC

Ksiażkiewicz, S. (2012) Quantitative or qualiitative transport planning?. An interdisciplinary geographic perspective. Revista Prace Geograficzne, 130, 131-139. https://doi. org/10.4467/20833113PG.12.024.0665 ARTIC

Malvicino y Yoguel (2015). Big data: avances recientes a nivel internacional y perspectivas para el desarrollo local. Centro de Estudios Interdisciplinarios en Ciencia, Tecnología e Innovación, Documento de Trabajo №3. http://www.ciecti.org.ar/wp-content/uploads/2017/07/DT3-BigData-avances-yperspectivas-de-desarrollo-local.pdf

Mauttone, A., y Hernández, D. (2017). Encuesta de movilidad del área metropolitana de Montevideo. Principales resultados e indicadores. CAF-Banco de Desarrollo de América Latina, Intendencia de Montevideo, Intendencia de Canelones, Intendencia de San José, Ministerio de Transporte y Obras Públicas, Universidad de la República, PNUD Uruguay. http://scioteca.caf.com/handle/123456789/1078

Montoya, V. (2020). Domestic workers' commutes in Bogotá: Transportation, gender and social exclusion. Revista Transportation Research Part A, 139, 400-411. https://doi.org/10.1016/j.tra.2020.07.019

Moscoso, M.; van Laake, T.; Quiñones, L.; Pardo, C. e Hidalgo, D. (2020). Transporte urbano sostenible en América Latina: evaluaciones y recomendaciones para políticas de movilidad. GIZ TUMI, Despacio. https://docplayer.es/178299927-Transporte-urbano-sostenible-en-america-latina-evaluacionesy-recomendaciones-para-politicas-de-movilidad.html

Neri, V.; Galeota, C. y Capellii, L. (2019). La utilización de las encuestas de movilidad domiciliaria para un análisis de accesibilidad. Aplicación para el caso de acceso a Centros Educativos en el Área Metropolitana de Buenos Aires. Revista Transporte y Territorio, 23, 71-81. https://doi.org/10.34096/ $\underline{\text { rtt.i23.9657 }}$

Ortuzar, J. y Willumsen, L. (2007). Modelling Transport. (L. Vozzi, Trad). Municipalidad de Rosario, Unidad de Planificación Estratégica de Movilidad, Tránsito y Transporte Multimodal. (Obra original publicada en 1990)

Pizarro, A. (2013). Políticas integradas y sostenibles de movilidad: revisión y propuesta de un marco conceptual. Comisión Económica para América Latina y el Caribe, Boletín FAL. Edición 323, 7, pp. 1-9. http://hdl. handle.net/11362/36168

Proyecto MODURAL (18 de Agosto de 2021). Atlas Bogotá y Lima. https://modural.hypotheses.org/1263

Richardson, A.; Ampt, L. y Meyburg, A. (1995). Survey Methods for Transport Planning. Eucalyptus Press.

Sánchez de Madariaga, I. (2009). Vivienda, movilidad y urbanismo para la igualdad en la diversidad: ciudades, género y dependencia. Revista Ciudad y Territorio. Estudios Territoriales, XLI(161-162), 581-597. https://recyt.fecyt.es/index.php/CyTET/article/view/75953/46360

Secretaría de Transporte (2011a). Informe de resultados: Encuesta de Movilidad Domiciliaria del Área Metropolitana de Rosario. Ministerio de Planificación Federal, Inversión Pública y Servicios, Secretaría de Transporte, Proyecto de Transporte Urbano de Buenos Aires (PTUBA). http://datar.info/dataset/ encuesta-origen-destino-2008-rosario/resource/4026f26b-a2db-4a3b-9642-65216ab7eb6d

Secretaría de Transporte (2011b). Base de datos. Encuesta de Movilidad Domiciliaria (ENMODO) AMBA 20092010. Ministerio de Planificación Federal, Inversión Pública y Servicios, Secretaría de Transporte, Proyecto de Transporte Urbano de Buenos Aires (PTUBA). https://www.argentina.gob.ar/transporte/ dgppse/publicaciones/encuestas

Secretaría Distrital de Movilidad (2015). Base de datos Encuesta de Movilidad 2015. Alcaldía Mayor de Bogotá D.C. https://simur.gov.co/encuestas-de-movilidad

Secretaría Distrital de Movilidad (2019). Base de datos Encuesta de Movilidad 2019. Alcaldía Mayor de Bogotá D.C. https://simur.gov.co/encuestas-de-movilidad

Subsecretaría de Transportes (s.f). Encuestas de Movilidad. Gobierno de Chile, Ministerio de Transportes y Telecomunicaciones, Programa de Vialidad y Transporte Urbano. http://www.sectra.gob.cl/ encuestas_movilidad/encuestas_movilidad.htm 
Stopher, P. (2009). The Travel Survey Toolkit: Where to From Here?. En: P. Bonnel, M. Lee-Gosselin, J. Zmud, J.L. Madre (Eds.), Transport survey methods: keeping up with a changing world. (pp. 15-46). Emerald Group Publishing Limited

Stopher, P. R. (1996). Household travel surveys: Cutting-edge concepts for the next century. [Presentación de ponencia]. Conference on Household Travel Surveys: New Concepts and Research Needs, Conference Proceedings 10, Transportation Research Board, Irvine, Estados Unidos. http://onlinepubs.trb.org... onf/1995/cp10/cp10-003.pdf

Terrile, H. (Abril, 2021). Encuestas Origen Destino de la Región Metropolitana de BuenosAires (ENMODO) 2008-2020. [Webinar] Comisión Económica para América Latina (CEPAL). https://www.cepal.org/ sites/default/files/presentations/buenos-aires-hugo-terrile.pdf

Vasconcelllos, E. (2015). Transporte urbano y movilidad: reflexiones y propuestas para países en desarrollo. UNSAM Edita.

Vasconcellos, E. y Mendonça, A. (2016). Observatorio de Movilidad Urbana: Informe 2015-2016. Resumen Ejecutivo. CAF-Banco de Desarrollo de América Latina, http://scioteca.caf.com/ handle/123456789/981

Yankelevich, D.; Echague J.; Melani, C.; Nerome, M.; Artopoulos, A. (2016). Big Bang Data en Transporte. Cómo Big Data puede ensamblar soluciones de ingeniería en transporte con la gestión sociotécnica de la movilidad en la ciudad. https://www.academia.edu/33028381/Big_Bang_Data_en_Transporte

Yomal, A. (2017). La incidencia de la accesibilidad al transporte público en el nivel de empleo en la Región Gran Buenos Aires: un modelo de regresión lineal. Revista Transporte y Territorio, 18, 246-263. https://doi.org/10.34096/rtt.i18.4936 